
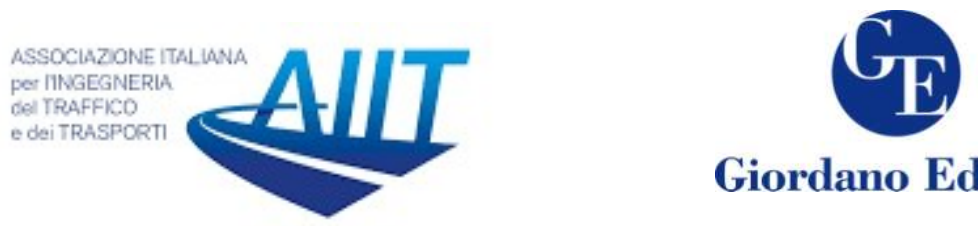

Giordano Editore

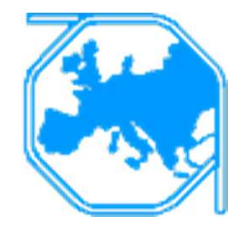

\title{
Microsimulation and the Evaluation of Safety Levels in the Presence of Roadside Obstacles
}

\author{
Vittorio Astarita ${ }^{1 *}$, Demetrio Carmine Festa ${ }^{1}$, \\ Vincenzo Pasquale Giofrè ${ }^{1}$
}

${ }^{1}$ Università della Calabria, Rende (CS), Italy

\begin{abstract}
Traffic microsimulation has been used for the analysis of road safety. In particular, some studies have confirmed that the reproduction by simulation of user behaviour under different traffic flows and geometry conditions can identify near crashes events that are a good base to estimate real crash risk. According to recent researches it appears that microsimulation tools can evaluate road safety performance and allow engineers to take appropriate countermeasures at specific points of the road network.

The results of these approaches have been promising, though, all ongoing research has overlooked one important issue in the estimation of traffic safety levels: single vehicle crashes. According to statistics, collisions with fixed objects result in above $40 \%$ of all vehicle fatal crashes. Common used safety indicators are limited in their application since, in fact, they are based on conflicts techniques that do not consider roadside obstacles and barriers.

The objective of this paper is to present a specific application of microsimulation software which is able to consider also potential conflicts with roadside objects. A specific microsimulation model add-on has been developed for the estimation of new road safety indicators that considers also potential crashes with roadside objects. First results are very promising and the developed software was applied on Tritone microsimulation package and can be used as an add-on also for other common used microsimulation packages such as Vissim and Aimsun.
\end{abstract}

Keywords: Traffic simulation; traffic safety; traffic theory; crash simulation.

\section{Introduction}

Several commercial microsimulation packages for road traffic have been developed, which are useful to asses road projects and traffic control scenarios by evaluating detailed measure of performances on the foreseen road traffic dynamic. However, most microsimulation packages do not provide measure of performances for traffic safety. With microsimulation packages, it is possible to obtain detailed values at a micro-level for pollution emission, fuel consumption, trip travel time and speed, though only recently road safety performances indexes have been considered inside microsimulation

\footnotetext{
${ }^{*}$ Corresponding author: Vittorio Astarita (vittorio.astarita@unical.it)
} 
packages (G. Guido, Astarita, Giofré, and Vitale, 2011), (V. Astarita, Giofré, Guido, and Vitale, 2011), (V Astarita et al., 2017).

At the University of Calabria, since 1996, research was devoted to traffic simulation (Vittorio Astarita, 1996),(V. Astarita, Florian, and Musolino, 2001) and the possibility of using new technologies and microsimulation to increase sustainability (Giuseppe Guido et al., 2013),(V. Astarita, Guido, Mongelli, and Giofrè, 2015),(Festa, Mongelli, Astarita, and Giorgi, 2013)(V. Astarita, Guido, Mongelli, and Giofrè, 2014). With this aim a specific traffic simulation package was developed named Tritone (Vittorio Astarita, Guido, Vitale, and Giofrè, 2012)(Giofrè, Maciejewski, Merkisz-Guranowska, Piątkowski, and Astarita, 2013)(V. Astarita, Guido, Vitale, and Gallelli, 2014). Tritone in the early design phase was developed to provide, not only the time varying dynamics of traffic flows and all standard performance measures (commonly produced as output of both static and dynamic transportation system modeling) but also road safety performance indices.

The common procedure to evaluate safety levels with microsimulation is based on conflict theory. Conflict based safety performance indicators are evaluated on the vehicle trajectories. When vehicle trajectories intersect with little time interval between the passages of two different vehicles a conflict is considered. Depending on the exact definition of a conflict different indicators have been developed which offer a measure of how safety is affected ((Hayward, 1971),(Minderhoud and Bovy, 2001),(Huguenin, Torday, and Dumont, 2005),(Saccomanno, Cunto, Guido, and Vitale, 2008),(G. Guido, Saccomanno, Vitale, Astarita, and Festa, 2011),(Giuseppe Guido, Astarita, Giofré, and Vitale, 2011), (Tarko, 2012),(Laureshyn, De Ceunynck, Karlsson, Svensson, and Daniels, 2017)).

According to the Federal Highway Administration (Gettman and Head, 2003), conflict based safety performance measures that are well defined can be useful to spot dangerous interactions in traffic scenarios and in defining the right safety investments that will reduce risks and involve a limited cost.

Vehicle conflicts have been manually calculated in early applications in USA and in the Swedish traffic conflict technique and have been well represented by Hydén (Technology, Department, and 1987, n.d.) in terms of a "safety performance pyramid" (see Fig. 1)

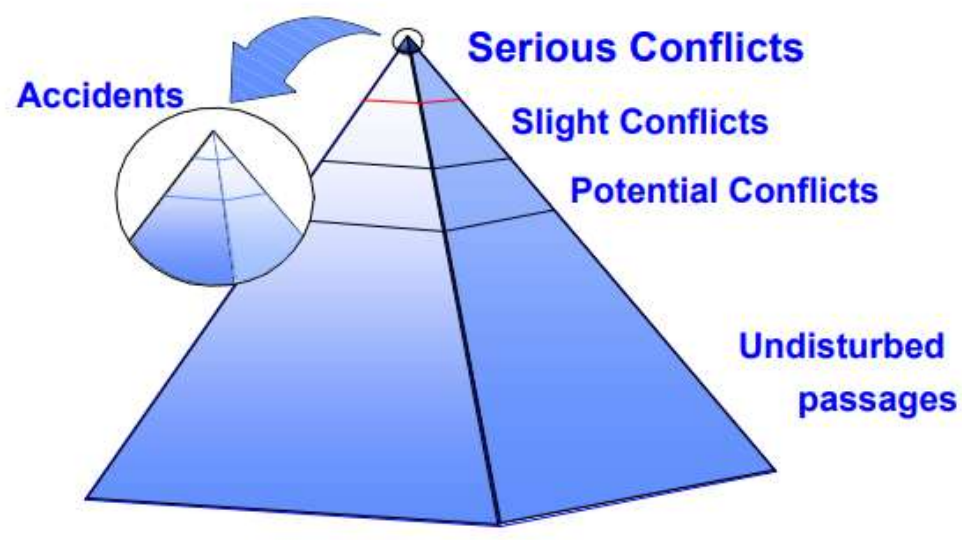

Figure 1: Hydén safety pyramid.

Source: http://www.tft.lth.se/fileadmin/tft/video_in_traffic/Swedish_conflict_technique.pdf, n.d.

Hydén's pyramid represents all possible interactions between vehicles, from common undisturbed events at the base of the pyramid to less frequent higher risk events nearer the peak (i.e. accidents). The theory behind this approach is that accidents data are only 
a part of the information on safety conditions in a traffic scenario. A more complete safety evaluation should consider also vehicle interactions which are dangerous and did not, luckily, result in an accident. Conventional safety analysis methods can produce accident prediction models which are based only on past crash events, and thus do not take into account all dangerous interactions that have not ended in a reported crash.

Microsimulation packages are able to reproduce vehicle trajectories on which the conflict techniques can be applied to evaluate safety levels. This allows the use traffic simulation sampling of safety performance indicators for alternative traffic scenarios before actually implementing them on the field. With microsimulation packages Engineers are allowed to compare different traffic planning solutions based not only on classical traffic performances (such as travel times, pollutants emissions and fuel consumption) but also according to safety evaluations based on traffic simulations.

Most microsimulation packages can be interfaced with SSAM Software (Gettman, Sayed, $\mathrm{Pu}$, and Shelby, 2008) to perform safety evaluations. The SSAM (Surrogate Safety Assessment Model) software package proposes to offer to planners, researchers and companies a tool to assess the safety of an intersection by estimating the frequency of conflicts.

The limitation of use to an intersection level is originated in the common used conflict theory which is not able to identify dangers caused by the interactions of vehicles with road-side obstacles and objects (that will be further discussed in the following).

The SSAM software packages processes the trajectory files obtained as output of a micro-simulation modeling program, such as Aimsun $^{\mathrm{TM}}$ (Gipps, 1981), VISSIM ${ }^{\mathrm{TM}}$ (Wiedemann, 1974, 1991), TEXAS ${ }^{\mathrm{TM}}$ or Paramics ${ }^{\mathrm{TM}}$ (Fritzsche and Ag, 1994), evaluating each individual vehicle interaction and conflict according to criteria which can determine if there is a point of conflict and which category it belongs to. At the end of the processing procedure SSAM presents the results in tables, allowing the user to filter them according to parameters of his choice.

Many are the traffic conflict indicators that have been proposed to asses safety levels, among them: time to collision (TTC, see also : (Minderhoud and Bovy, 2001),(Lee, 1976),(Vogel, 2003)) post encroachment time (PET, see: (Cooper, 2011)), initial deceleration rate (DR, see:(Pirdavani, Brijs, Bellemans, and Wets, 2010)), maximum of the speeds of the two vehicles involved in the conflict event (MaxS, (Shelby, 2011)), maximum relative speed of the two vehicles involved in the conflict event (DeltaS, (Shelby, 2011)), deceleration rate to avoid the crash (DRAC, (Qu, Kuang, Oh, and Jin, 2014)), and proportion of stopping distance (PSD, (G. Guido, Saccomanno, et al., 2011) ).

Though, a serious problem was, almost, never addressed in traffic conflict techniques: an enormous number of vehicle crashes occur with isolated vehicles crashing into roadside objects or obstacles (some exceptions can be found such as in: (Tarko, 2012)).

This crash typology is not considered in common proposed and adopted traffic conflict indicators.

This paper introduces a new software micro-simulation add-on package which is able to evaluate also potential risks connected with road-side obstacles.

The paper is structured in the following way: in section 2 some specific techniques for traffic safety evaluation are discussed evidencing the limits of current software packages, in section 3 a new simulation technique for crash risk evaluation which considers road side objects is introduced, in section 4 some preliminary results are introduced and finally in section 5 conclusions are drawn. 


\section{Safety evaluations based on crash data, safety audit and micro-simulation}

Road safety levels are traditionally established on the base of the past history of recorded crash data (E. Hauer, 1986), (Jovanis and Chang, 1986), (Miaou and Lum, 1993), (Miaou, 1994), (Shankar, Mannering, and Barfield, 1995), (E. (Ezra) Hauer, 1997), (Abdel-Aty and Radwan, 2000), (Yan, Radwan, and Abdel-Aty, 2005). Statistical analysis is performed on crash data establishing statistical relationships that can predict an expected number of crashes. This approach has some disadvantages: it cannot be applied to new projects because there is not an established crash data set and the assessment of safety interventions thus is based on difficult to implement statistical analogies with similar situations. These analyses require a cultural background and an access to crash data that is outside the normal practitioner practice. Even when a specific black spot is identified it is not always straightforward for scientists to establish causes and evaluate impacts of different solutions. Safety assessments that are based on historical crash data are "reactive" instead of being "proactive".

An alternative "proactive" common approach to establish traffic safety is the road safety audit where an independent team of experts is called to evaluate possible black spots and possible safety interventions. Road safety audits can be performed on existing roads to asses safety levels and to identify possible interventions or can be applied to roadwork projects from the design phase to the end of the project realization. Road safety audit practice is dangerously reliant on the knowledge and training of the experts that perform the audit. It must be noted than in most countries there is a lack of formal and robust certification for this kind of experts. Road Safety Audits of two different experts can lead to very different results and a Delphi methodology (Mbakwe, Saka, Choi, and Lee, 2016) is not always applicable. Safety is a complicated issue and the notion that a human observer can perform all calculation that would be necessary to consider all potential vehicle interactions just by observation it is debatable. For this reason the evaluation of road safety levels with microsimulation or with more formal methodologies would help safety auditors to perform evaluations and offer a more quantitative and objective methodological base to assess safety.

For this reason micro-simulation has recently been considered for the evaluation of traffic safety levels by applying conflict based indicators to alternative scenarios. Crash data, observed and simulated conflicts have been evaluated producing good enough results in many works: (Dijkstra et al., 2010),(Caliendo and Guida, 2012),(El-Basyouny and Sayed, 2013),(Huang, Liu, Yu, and Wang, 2013),(Zhou and Huang, 2013),(Ambros, Turek, and Paukrt, 2014),(Shahdah, Saccomanno, and Persaud, 2014),(Shahdah, Saccomanno, and Persaud, 2015),(Cafiso, D'Agostino, Kieć, and Bak, 2018),(Olszewski, Czajewski, Osińska, Szagała, and Włodarek, 2019),(Tarko, 2018). Microsimulation and conflict based techniques have also been applied to establish the safety levels after the introduction of connected and autonomous vehicles (Zha, Songchitruksa, and Balke, 2014),(Morando, Tian, Truong, and Vu, 2018),(Vittorio Astarita, Festa, Giofrè, Guido, and Vitale, 2018). Tritone was developed to explicitly use these conflict techniques to offer an easy tool for engineers, avoiding the complication of using two different packages (micro-simulation + SSAM package) and to automatically produce risks maps.

Although (as introduced above), there is one basic problem in current conflict based techniques: they originate from intersection analysis and do not consider conflicts between vehicles that are traveling on non-conflicting trajectories and conflicts between isolated vehicles and road side objects and obstacles. In (Treese, 2017) 3 millions data 
crash records relative to Florida state from 2006 to 2013 were used to show that over 500000 were single-vehicle accidents with road side objects or barriers (among them 47,341 were tree-related accidents). In (Holdridge, Shankar, and Ulfarsson, 2005) it is stated that in the United States, crashes with road side objects are $19 \%$ of all USA reported crashes and they result in $44 \%$ of all fatal crashes.

For this reason we developed a new procedure for crash simulation based on the explicit simulation of human potential errors that is introduced in the next section.

\section{Simulation of crashes in Tritone: the Zombie-driver add-on module extends a previous procedure to establish road side hazards to every possible traffic scenario in microsimulation}

Tritone traffic simulator was developed in the University of Calabria as a research tool that allows users to apply many different modelling formulations for both the core simulation engine and for the evaluation of performances. Different or custom carfollowing models can be used in the simulation and different models can be also used for Lane-Changing modelling, Gap-Acceptance, Over-taking, fuel consumption and pollutant emissions.

Tritone is able to also simulate Floating Car Data (FCD). Tritone can, in fact, simulate the presence of a Global Navigation Satellite System (GNSS) signal on a vehicle. This feature allows to reproduce complex ITS systems allowing also to test different algorithms and the results in term of traffic safety.

Some new features have been introduced in Tritone and were described in (V Astarita et al., 2017). The proposed methodology (called Zombie-driver) has been developed inside the Tritone micro-simulation package (since 2018) but can be applied also to other software packages whenever the simulated vehicle trajectories are produced and can be exported. The methodology intends to assess safety levels in a similar way as what is done with established safety performance conflict techniques. All the fundamental theory at the base of the Swedish traffic conflict technique is retained and extended in such a way that conflicts are not anymore limited to vehicles that are traveling on trajectories which intersect.

The main problem in the application of SSAM software and in the Swedish conflict methodology is that the two cases depicted in figure 2 do not generate any conflict.

The new methodology that has been implemented and inserted in the Tritone package is able to deal with this kind of conflicts and is described in detail in (Vittorio Astarita and Giofré, 2019). The methodology originates from the concepts presented in the Roadside Safety Analysis Program (RSAP) developed in the National Cooperative Highway Research Program (NCHRP) (Mak et al., 2003). RSAP was developed to economically assess the risk caused by road-side objects and obstacles aiming at an economical and quantitative evaluation of the road safety risks caused by this type of impact. 


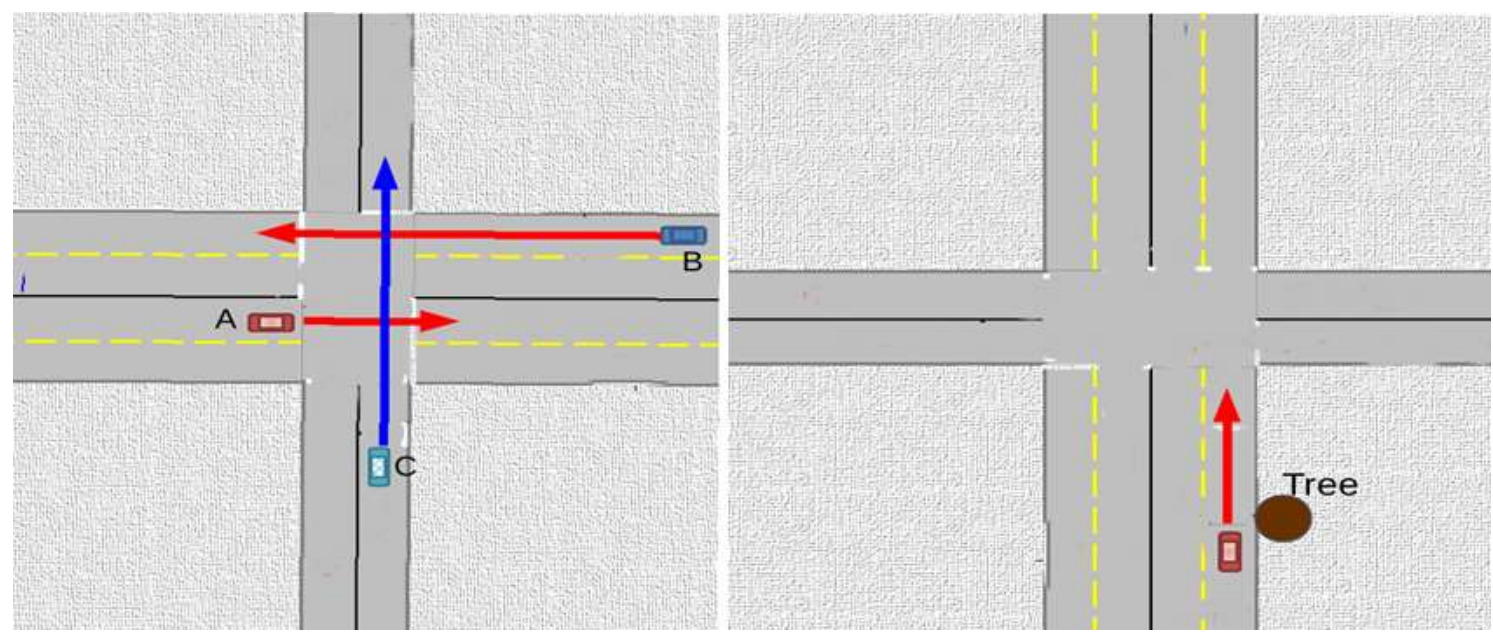

Figure 2: (a) Traffic scenario in which A and B do not generate a conflict according to SSAM software; (b) Traffic scenario in which a car drives close to a roadside dangerous object and that is not considered as a conflict according to the Swedish conflict methodology.

RSAP procedure is simply that of generating vehicle anomalous trajectories with a defined encroachment speed and angle and evaluating the potential outcome of a crash with road-side objects. The RSAP approach does consider only isolated vehicle crashes. Our methodology combines the potential of traffic conflict indicators (as those generated by the Swedish traffic conflict technique) with the capacity of assessing road side obstacles effects on safety as in RSAP. The idea is to generate potential crashes by generating a human error which turns into a deviated trajectory (exactly as in RSAP). The deviated trajectory is projected on the micro-simulated scenario and on the map of road-side objects and barriers to check if there is a crash. In case there is a crash the energy of the crash is evaluated by calculations that are performed on the known dynamics of the simulated crash. Two kind of crashes are possible: crashes between vehicles and crashes of isolated vehicles with road-side objects. In the following figures 3 and 4 some generated deviated trajectories are shown.

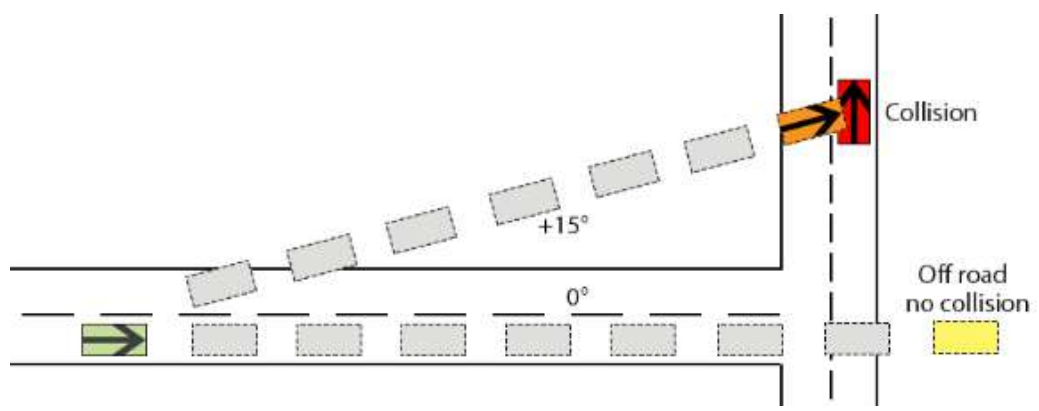

Figure 3: A deviated trajectory with a $15^{\circ}$ angle determines the exit from the road and a collision. 


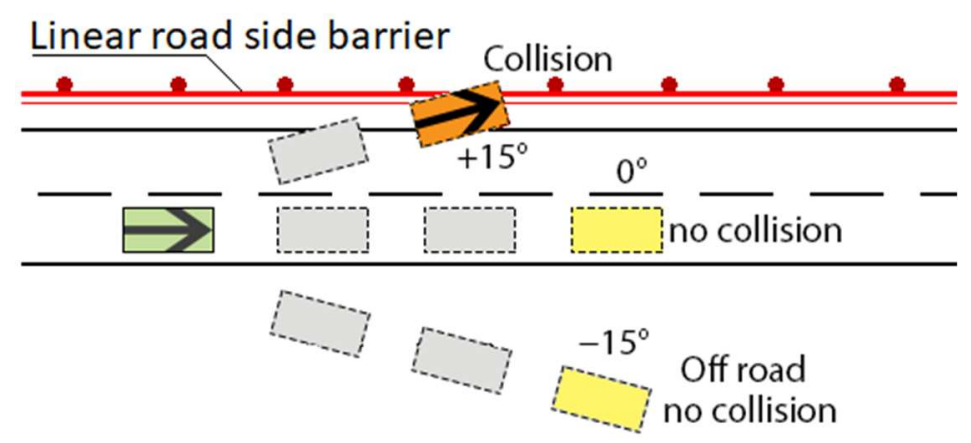

Figure 4: Three deviated trajectories: only one determines a collision with the left road side barrier.

\section{Some results and discussion}

A fictional traffic scenario has been proposed to safety audit experts who on the base of their knowledge have evidenced the following 8 dangerous points that are depicted in figure 5: an unsignalized intersection, a deviation of the road layout, trees (3 points), a dangerous turn, the unprotected corner at the start of a road side barrier and road signs placed in the middle of an intersection. The Zombie-driver software procedure has been applied to this scenario.

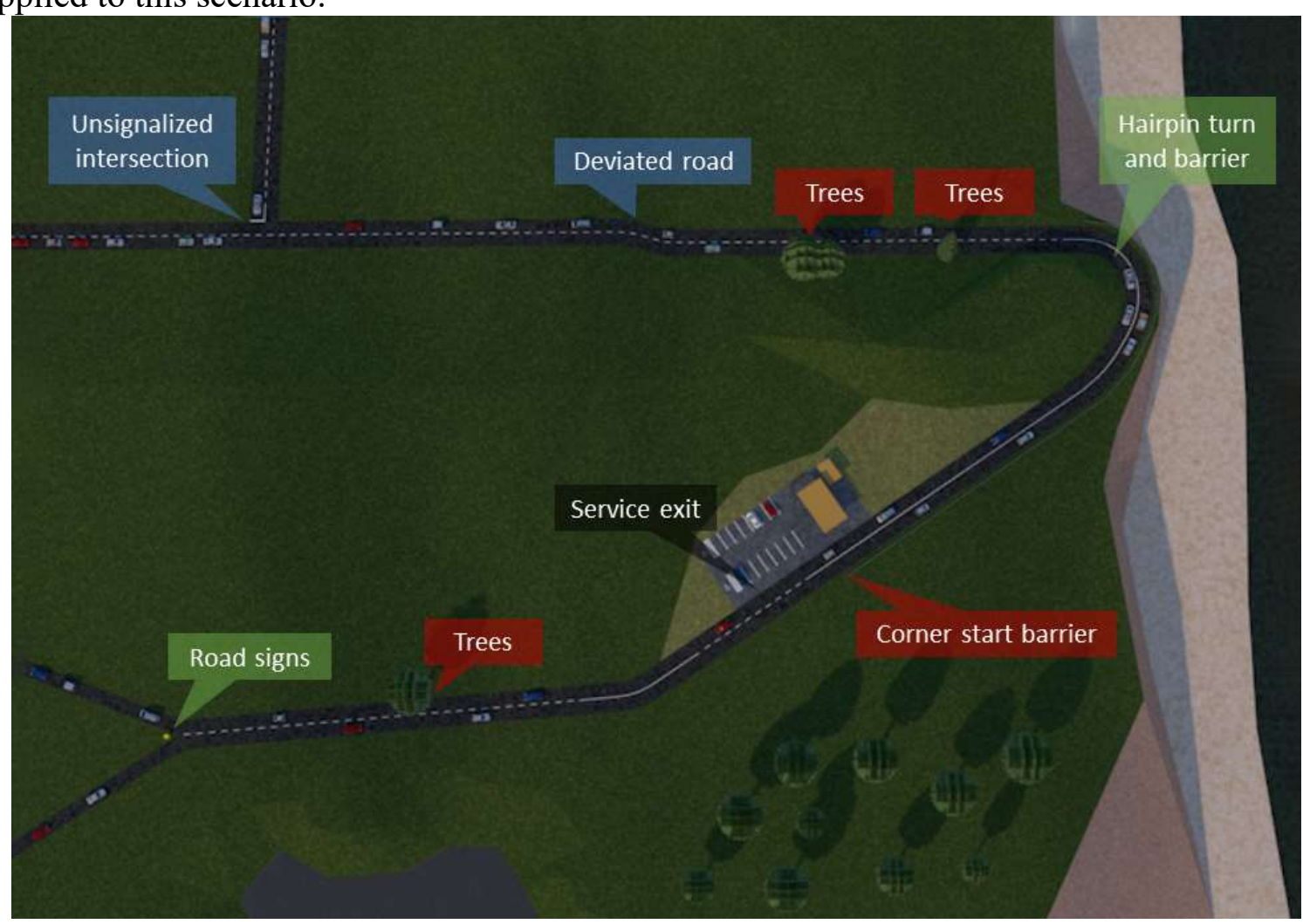

Figure 5: Test scenario with 8 different dangerous points. 


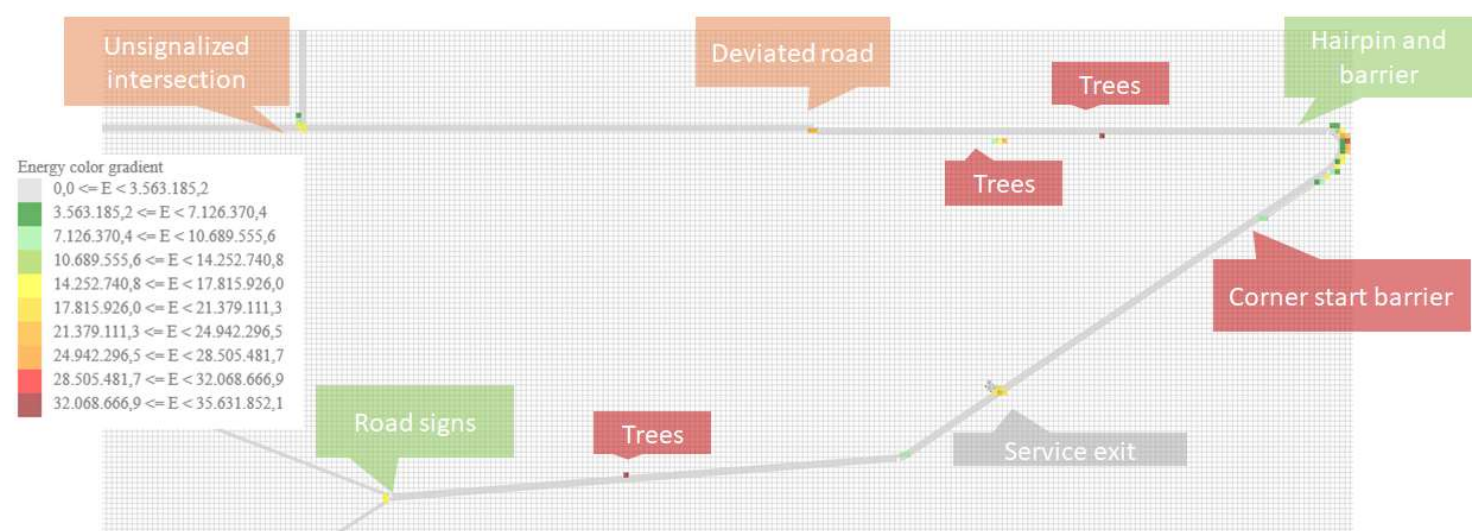

Figure 6: Six dangerous points can be easy spotted with high crash energy values.

The total energy for square meter of all generated crash is shown on the map in the following figure 6 after the application of a threshold to evidence the most dangerous points. Without any detailed calibration of the microsimulation model and without any calibration of the parameters of the procedure (standard values have been used) it is possible to identify six of the eight dangerous points. It must be noted that it would have been possible to identify exactly all the eight dangerous points with a different energy threshold and different parameters of the procedure.

The procedure has many calibration parameters and research efforts will have to be devoted to make confrontations with real crash data in order to obtain the best parameters that have the potential of giving an accurate evaluation of the risk of any traffic scenario.

The production of map risks even without a calibration of parameters means that the procedure is possibly very stable and not sensitive to a variation in parameters. More research efforts will have also to be devoted to a sensitivity analysis (which is outside of the scope of this work) for a procedure that can be very useful to road engineers, developers and road administrations in the task of easily identify safety problems on a network and test possible alternative solutions.

\section{Conclusions}

This paper introduces a specific new procedure and the implementation in the form of a software package which is able to assess road safety considering also potential conflicts with roadside objects. Some of the principles that are at the base of this specific microsimulation model add-on are discussed. The procedure can be applied on common microsimulation packages once vehicle trajectories and road side barrier and obstacles are known.

\section{References}

Abdel-Aty, M. A., Radwan, A. E. (2000). "Modeling traffic accident occurrence and involvement". Accident Analysis and Prevention. https://doi.org/10.1016/S00014575(99)00094-9

Ambros, J., Turek, R., Paukrt, J. (2014). "Road safety evaluation using traffic conflicts : pilot comparison of micro-simulation and observation.". International Conference on Traffic and Transport Engineering November 27-28,2014. 
Astarita, V., Florian, M., Musolino, G. (2001). "A microscopic traffic simulation model for the evaluation of toll station systems". IEEE Conference on Intelligent Transportation Systems, Proceedings, ITSC.

Astarita, V., Giofré, V., Guido, G., Vitale, A. (2011). "Investigating road safety issues through a microsimulation model". Procedia - Social and Behavioral Sciences, 20. https://doi.org/10.1016/j.sbspro.2011.08.028

Astarita, V., Guido, G., Mongelli, D., Giofrè, V. P. (2015). "A co-operative methodology to estimate car fuel consumption by using smartphone sensors". Transport, 30(3). https://doi.org/10.3846/16484142.2015.1081280

Astarita, V., Guido, G., Mongelli, D. W. E., Giofrè, V. P. (2014). "Ecosmart and TutorDrive: Tools for fuel consumption reduction". Proceedings of 2014 IEEE International Conference on Service Operations and Logistics, and Informatics, SOLI 2014. https://doi.org/10.1109/SOLI.2014.6960716

Astarita, V., Guido, G., Vitale, A., Gallelli, V. (2014). "Analysis of non-conventional roundabouts performances through microscopic traffic simulation". In Applied Mechanics and Materials (Vol. https://doi.org/10.4028/www.scientific.net/AMM.505-506.481

Astarita, V, Giofrè, V. P., Guido, G., Vitale, A., Festa, D., Vaiana, R., ... Gallelli, V. (2017). "New features of Tritone for the evaluation of traffic safety performances". Transport Infrastructure and Systems, 625-632. https://doi.org/10.1201/9781315281896-82

Astarita, Vittorio. (1996). "Flow propagation description in dynamic network loading models". In Proceedings of the International Conference on Applications of Advanced Technologies in Transportation Engineering.

Astarita, Vittorio, Festa, D. C., Giofrè, V. P., Guido, G., Vitale, A. (2018). "The use of Smartphones to assess the Feasibility of a Cooperative Intelligent Transportation Safety System based on Surrogate Measures of Safety". Procedia Computer Science, 134, pp. 427-432. https://doi.org/10.1016/j.procs.2018.07.188

Astarita, Vittorio, Giofré, V. P. (2019). "From traffic conflict simulation to traffic crash simulation: Introducing traffic safety indicators based on the explicit simulation of potential driver errors". Simulation Modelling Practice and Theory. https://doi.org/10.1016/J.SIMPAT.2019.03.003

Astarita, Vittorio, Guido, G., Vitale, A., Giofrè, V. P. (2012). "A new microsimulation model for the evaluation of traffic safety performances". European Transport, (51), pp. 1-16. https://doi.org/10.1016/j.sbspro.2012.09.817

Cafiso, S., D’Agostino, C., Kieć, M., Bak, R. (2018). "Safety assessment of passing relief lanes using microsimulation-based conflicts analysis". Accident Analysis and Prevention. https://doi.org/10.1016/j.aap.2017.07.001

Caliendo, C., Guida, M. (2012). "Microsimulation Approach for Predicting Crashes at Unsignalized Intersections Using Traffic Conflicts". Journal of Transportation Engineering. https://doi.org/10.1061/(ASCE)TE.1943-5436.0000473

Cooper, P. J. (2011). "Experience with Traffic Conflicts in Canada with Emphasis on "Post Encroachment Time" Techniques". In International Calibration Study of Traffic Conflict Techniques. https://doi.org/10.1007/978-3-642-82109-7_8

Dijkstra, A., Marchesini, P., Bijleveld, F., Kars, V., Drolenga, H., van Maarseveen, M. (2010). "Do Calculated Conflicts in Microsimulation Model Predict Number of Crashes?". Transportation Research Record: Journal of the Transportation Research Board. https://doi.org/10.3141/2147-13 
El-Basyouny, K., Sayed, T. (2013). "Safety performance functions using traffic conflicts". Safety Science. https://doi.org/10.1016/j.ssci.2012.04.015

Festa, D. C., Mongelli, D. W. E., Astarita, V., Giorgi, P. (2013). "First results of a new methodology for the identification of road surface anomalies". Proceedings of 2013 IEEE International Conference on Service Operations and Logistics, and Informatics, SOLI 2013. https://doi.org/10.1109/SOLI.2013.6611408

Fritzsche, H., Ag, D. (1994). "A model for traffic simulation". Traffic Engineering and Control, 35, pp. 317-321.

Gettman, D., Head, L. (2003). "Surrogate Safety Measures from Traffic Simulation Models". Transportation Research Record: Journal of the Traportation Research Board. https://doi.org/10.3141/1840-12

Gettman, D., Sayed, T., Pu, L., Shelby, S. (2008). "Surrogate Safety Assessment Model and Validation". Fhwa-Hrt-08--51. https://doi.org/10.3109/17453674.2011.581265

Giofrè, V. P., Maciejewski, M., Merkisz-Guranowska, A., Piątkowski, B., Astarita, V. (2013). "Real road network application of a new microsimulation tool: TRITONE". Archives of Transport, 27-28(3-4).

Gipps, P. G. (1981). "A behavioural car-following model for computer simulation". Transportation Research Part B. https://doi.org/10.1016/0191-2615(81)90037-0

Guido, G., Astarita, V., Giofré, V. P., Vitale, A. (2011). "Safety performance measures: A comparison between microsimulation and observational data". Procedia - Social and Behavioral Sciences, 20, 217-225. https://doi.org/10.1016/j.sbspro.2011.08.027

Guido, G., Saccomanno, F., Vitale, A., Astarita, V., Festa, D. (2011). "Comparing safety performance measures obtained from video capture data". Journal of Transportation Engineering, 137(7). https://doi.org/10.1061/(ASCE)TE.19435436.0000230

Guido, Giuseppe, Astarita, V., Giofré, V. P., Vitale, A. (2011). "Safety performance measures: A comparison between microsimulation and observational data". Procedia - Social and Behavioral Sciences, 20, 217-225. https://doi.org/10.1016/j.sbspro.2011.08.027

Guido, Giuseppe, Vitale, A., Saccomanno, F. F., Festa, D. C., Astarita, V., Rogano, D., Gallelli, V. (2013). "Using Smartphones as a Tool to Capture Road Traffic Attributes". Applied Mechanics and Materials. https://doi.org/10.4028/www.scientific.net/AMM.432.513

Hauer, E. (1986). "On the estimation of the expected number of accidents". Accident Analysis and Prevention. https://doi.org/10.1016/0001-4575(86)90031-X

Hauer, E. (Ezra). (1997). Observational before--after studies in road safety : estimating the effect of highway and traffic engineering measures on road safety. Pergamon.

Hayward, J. (1971). "Near misses as a measure of safety at urban intersections". PhD Thesys, Department of Civil Engineering, The Pennsylvania State University.

Holdridge, J. M., Shankar, V. N., Ulfarsson, G. F. (2005). "The crash severity impacts of fixed roadside objects". Journal of Safety Research. https://doi.org/10.1016/j.jsr.2004.12.005

Huang, F., Liu, P., Yu, H., Wang, W. (2013). "Identifying if VISSIM simulation model and SSAM provide reasonable estimates for field measured traffic conflicts at signalized intersections". Accident Analysis and Prevention. https://doi.org/10.1016/j.aap.2012.08.018

Huguenin, F., Torday, A., Dumont, A. (2005). "Evaluation of traffic safety using 
microsimulation". 5th Swiss Transport Research Conference.

Jovanis, P. P., Chang, H.-L. (1986). "Modeling the relationship of accidents to miles traveled". Transportation Research Board.

Laureshyn, A., De Ceunynck, T., Karlsson, C., Svensson, Å., Daniels, S. (2017). "In search of the severity dimension of traffic events: Extended Delta-V as a traffic conflict indicator". Accident Analysis and Prevention. https://doi.org/10.1016/j.aap.2016.09.026

Lee, D. N. (1976). "A theory of visual control of braking based on information about time to collision". Perception. https://doi.org/10.1068/p050437

Mak, K. K., Sicking, D., National Cooperative Highway Research Program., National Research Council (U.S.). Transportation Research Board., American Association of State Highway and Transportation Officials., United States. Federal Highway Administration. (2003). Roadside Safety Analysis Program (RSAP)-- engineer's manual. Transportation Research Board.

Mbakwe, A. C., Saka, A. A., Choi, K., Lee, Y. J. (2016). "Alternative method of highway traffic safety analysis for developing countries using delphi technique and Bayesian network". Accident Analysis and Prevention. https://doi.org/10.1016/j.aap.2016.04.020

Miaou, S. P. (1994). "The relationship between truck accidents and geometric design of road sections: Poisson versus negative binomial regressions". Accident Analysis and Prevention. https://doi.org/10.1016/0001-4575(94)90038-8

Miaou, S. P., Lum, H. (1993). "Modeling vehicle accidents and highway geometric design relationships". Accident Analysis and Prevention. https://doi.org/10.1016/0001-4575(93)90034-T

Minderhoud, M. M., Bovy, P. H. L. (2001). "Extended time-to-collision measures for road traffic safety assessment". Accident Analysis and Prevention. https://doi.org/10.1016/S0001-4575(00)00019-1

Morando, M. M., Tian, Q., Truong, L. T., Vu, H. L. (2018). "Studying the Safety Impact of Autonomous Vehicles Using Simulation-Based Surrogate Safety Measures". Journal of Advanced Transportation. https://doi.org/10.1155/2018/6135183

Olszewski, P., Czajewski, W., Osińska, B., Szagała, P., Włodarek, P. (2019). "Investigation of traffic conflicts at signalised intersections in Warsaw". MATEC Web of Conferences. https://doi.org/10.1051/matecconf/201926205009

Pirdavani, A., Brijs, T., Bellemans, T., Wets, G. (2010). "Evaluation of traffic safety at un-signalized intersections using microsimulation: A utilization of proximal safety indicators". Advances in Transportation Studies.

Qu, X., Kuang, Y., Oh, E., Jin, S. (2014). "Safety Evaluation for Expressways: A Comparative Study for Macroscopic and Microscopic Indicators". Traffic Injury Prevention. https://doi.org/10.1080/15389588.2013.782400

Saccomanno, F., Cunto, F., Guido, G., Vitale, A. (2008). "Comparing Safety at Signalized Intersections and Roundabouts Using Simulated Rear-End Conflicts". Transportation Research Record: Journal of the Transportation Research Board. https://doi.org/10.3141/2078-12

Shahdah, U., Saccomanno, F., Persaud, B. (2014). "Integrated traffic conflict model for estimating crash modification factors". Accident Analysis and Prevention. https://doi.org/10.1016/j.aap.2014.05.019

Shahdah, U., Saccomanno, F., Persaud, B. (2015). "Application of traffic 
microsimulation for evaluating safety performance of urban signalized intersections". Transportation Research Part C: Emerging Technologies. https://doi.org/10.1016/j.trc.2015.06.010

Shankar, V., Mannering, F., Barfield, W. (1995). "Effect of roadway geometrics and environmental factors on rural freeway accident frequencies". Accident Analysis and Prevention. https://doi.org/10.1016/0001-4575(94)00078-Z

Shelby, S. G. (2011). "Delta-V As a Measure of Traffic Conflict Severity". Traffic Safety.

Tarko, A. P. (2012). "Use of crash surrogates and exceedance statistics to estimate road safety". Accident Analysis and Prevention. https://doi.org/10.1016/j.aap.2011.07.008

Tarko, A. P. (2018). "Estimating the expected number of crashes with traffic conflicts and the Lomax Distribution - A theoretical and numerical exploration". Accident Analysis and Prevention. https://doi.org/10.1016/j.aap.2018.01.008

Technology, C. H.-B. L. I. of, Department, undefined, 1987, undefined. (n.d.). "The development of a method for traffic safety evaluation: The Swedish Traffic Conflicts Technique". Trid.Trb.Org.

Treese, J. Van. (2017). "Frequency and severity of tree and other fixed object crashes in Florida from 2006 to 2013". Presented at Trees People and the Build Environment 2017.

Vogel, K. (2003). "A comparison of headway and time to collision as safety indicators". Accident Analysis and Prevention. https://doi.org/10.1016/S0001-4575(02)00022-2

Wiedemann, R. (1974). Simulation des Straßenverkehrsflusses, Schriftenreihe des Instituts für Verkehrswesen der Universität Karlsruhe, Germany.

Wiedemann, R. (1991). "Modelling of RTI-Elements on multi-lane roads". In Advanced Telematics in Road Transport edited by the Commission of the European Community, DG XIII(Brussels).

Yan, X., Radwan, E., Abdel-Aty, M. (2005). "Characteristics of rear-end accidents at signalized intersections using multiple logistic regression model". Accident Analysis and Prevention. https://doi.org/10.1016/j.aap.2005.05.001

Zha, L., Songchitruksa, P., Balke, K. (2014). Next Generation Safety Performance Monitoring at Signalized Intersections Using Connected Vehicle Technology.

Zhou, H., Huang, F. (2013). "Development of Traffic Safety Evaluation Method based on Simulated Conflicts at Signalized Intersections". Procedia - Social and Behavioral Sciences. https://doi.org/10.1016/j.sbspro.2013.08.100 